Revista de Derecho

Universidad Católica del Norte

Sección: Estudios

Año 18 - No 1, 2011

pp. $171-182$

\title{
¿NO PUEDE APLICARSE El ARTíCULO 68 BIS DEL CÓDIGO PENAL DESPUÉS DE UNA COMPENSACIÓN RACIONAL ENTRE ATENUANTES Y AGRAVANTES?*
}

\author{
Guillermo Oliver CALDERÓN ${ }^{* *}$
}

RESUMEN: Una creciente tendencia jurisprudencial se niega a aplicar el artículo 68 bis del Código Penal cuando, en el proceso de determinación de la pena, una vez efectuada la compensación racional entre atenuantes y agravantes, subsiste una sola atenuante muy calificada. En este trabajo se somete a examen crítico dicha interpretación y se concluye que no existen razones sólidas que la justifiquen.

PALABRAS CLAVE: Atenuante - agravante - atenuante muy calificada - compensación racional - determinación de la pena.

\section{CAN'T ARTICLE 68 BIS OF THE CRIMINAL CODE BE APPLIED AFTER A RATIONAL COMPENSATION BETWEEN AGGRAVATING AND MITIGATING CIRCUMSTANCES?}

ABSTRACT: A growing jurisprudential trend refuses to apply article 68 bis of the Criminal Code when, while determining the penalty, and once a rational compensation has happened between the mitigating circumstances and the aggravating factors, there remains only one highly qualifying reason. This article critically assesses said interpretation and concludes that there are no base arguments to justify it.

KEY WORDS: Mitigating circumstances - aggravating factors - highly qualifying reason- rational compensation- penalty determination.

Este trabajo ha sido efectuado dentro del marco del proyecto de investigación Fondecyt No 1100901, "El proceso de determinación de la pena: estudio dogmático y crítico", en el que el autor se desempeña como investigador responsable.

Fecha de recepción: 10 de marzo de 2011.

Fecha de aceptación: 5 de abril de 2011.

** Doctor en Derecho por la Universidad de Barcelona (España). Profesor Adjunto de Derecho Penal, Pontificia Universidad Católica de Valparaíso (CHILE). Correo electrónico: guillermo.oliver@ucv.cl 


\section{INTRODUCCIÓN}

En la regulación del proceso de determinación de la pena que se contempla en las legislaciones penales de diversos países, como es sabido, es posible distinguir entre reglas de determinación legal de la pena -las que inciden en el marco penal aplicable a un delito- y reglas de individualización judicial de la misma -las que influyen en la concreción de la sanción dentro del marco penal ya determinado ${ }^{1}$. En el caso del Código Penal chileno (CP), dentro de las primeras se encuentran, entre otras, las que obligan a rebajar la pena señalada por la ley para el autor del delito consumado, cuando se trata de un cómplice o un encubridor o cuando el delito es tentado o frustrado (arts. 51 a 54 CP); y dentro de las segundas, la que permite al juez concretar la pena aplicable en atención al número y entidad de las circunstancias modificatorias de responsabilidad penal, y a la mayor o menor extensión del mal producido por el delito (art. $69 \mathrm{CP}$ ).

Una regla muy importante de determinación legal de la pena es la que se encuentra contenida en el artículo 68 bis $\mathrm{CP}^{2}$, conforme al cual, sin perjuicio de lo dispuesto en los artículos 65 a $68 \mathrm{CP}$, "cuando solo concurra una atenuante muy calificada el tribunal podrá imponer la pena inferior en un grado al mínimo de la señalada al delito".

Según nuestra percepción, en el último tiempo, en forma paulatina ha ido creciendo una tendencia jurisprudencial a aplicar esta disposición solamente cuando hay una única circunstancia modificatoria de responsabilidad que acompańa al delito, que es una atenuante y se la estima muy calificada. En otras palabras, los tribunales generalmente se niegan a aplicar este precepto cuando se presentan atenuantes y agravantes, y una vez

1 Así, aludiendo al Código Penal español, Mir Puig, Santiago (2004). Derecho Penal. Parte General, $7^{\text {a }}$ edición, Montevideo - Buenos Aires: B de F, pp. 715, 717 s., 723 . Véase también, Demetrio Crespo, Eduardo (1999). Prevención general e individualización judicial de la pena, Salamanca: Ediciones Universidad de Salamanca, pp. 41 ss.; Choclán Montalvo, José Antonio (1997). Individualización judicial de la pena. Función de la culpabilidad y la prevención en la determinación de la sanción penal, Madrid: Colex, pp. 107-109.

2 Mañalich Raffo, Juan Pablo (2010). “¿Discrecionalidad judicial en la determinación de la pena en caso de concurrencia de circunstancias atenuantes de la responsabilidad penal?", en Informes en Derecho, No 7, octubre, Doctrina Procesal Penal 2009, Centro de Documentación de la Defensoría Penal Pública, p. 45, quien considera, con razón, que la regla del citado artículo 68 bis pertenece al ámbito de la determinación legal de la pena y no al de la individualización judicial de la misma, porque incide en la fijación del marco penal dentro del cual el juez debe precisar la pena a imponer, al igual que las reglas de los artículos 65 a $68 \mathrm{CP}$. Que la alteración de dicho marco sea ordenada o solo permitida no interesa para estos efectos. En contra, Matus Acuña, Jean Pierre / Van Weezel de la Cruz, Alex (2002). "Comentario a los artículos 50 a 73", en Politoff Lifschitz, Sergio / Ortiz Quiroga, Luis (dirs.); Matus Acuña, Jean Pierre (coord.): Texto y comentario del Código Penal chileno, tomo I, Libro Primero - Parte General, Santiago: Editorial Jurídica de Chile, p. 324; VAN Weezel de la Cruz, Alex (1997). "Compensación racional de atenuantes y agravantes en la medición judicial de la pena", en Revista Chilena de Derecho, volumen 24, No 3, septiembre-diciembre, pp. 469-471. 
compensadas ellas racionalmente, subsiste una sola atenuante que es muy calificada. El objetivo de este breve trabajo es someter a examen crítico este proceder, pasando revista a los argumentos que se acostumbra esgrimir para justificarlo y exponiendo razones que permiten cuestionarlo.

\section{1) EL ARGUMENTO LITERAL}

Es común encontrar en la jurisprudencia fallos que, para negar aplicación al artículo 68 bis CP cuando tras una compensación entre circunstancias modificatorias de distinto orden subsiste una atenuante de gran entidad, utilizan un argumento gramatical que atiende a la palabra "solo" contenida en dicha disposición. Suele sostenerse por los tribunales que la letra de la ley (concretamente, la frase "...cuando solo concurra una atenuante muy calificada...”) obligaría a aplicar el precepto solamente cuando en el hecho se presente $a b$ initio una única circunstancia modificatoria que sea atenuante y que se considere muy calificada ${ }^{3}$. También un sector de la doctrina argumenta de esta forma ${ }^{4}$, aunque la mayor parte de los autores no se pronuncia sobre el tema que nos concierne, limitándose simplemente a reproducir el tenor de la mencionada disposición ${ }^{5}$.

3 Entre otras, véase Corte de Apelaciones de Valparaíso, sentencia de 19 de junio de 2009, dictada en causa rol No 550-2009; Corte de Apelaciones de Santiago, sentencia de 5 de febrero de 2009, dictada en causa rol No 2517-2008; y sentencia de 22 de mayo de 2006, dictada en causa rol No 794-2006; Corte de Apelaciones de Temuco, sentencia de 12 de noviembre de 2007, dictada en causa rol No 1153-2007; Corte De ApelaCiones de San Miguel, sentencia de 5 de mayo de 2006, dictada en causa rol No 329-2006; Corte de Apelaciones de Antofagasta, sentencia de 14 de septiembre de 2004, dictada en causa rol No 122-2004; y sentencia de 19 de agosto de 2002, dictada en causa rol No 092-2002. En contra, aceptando la aplicación del artículo 68 bis $\mathrm{CP}$ aun después de una compensación de circunstancias modificatorias, véase Corte Suprema, sentencia de 3 de enero de 2006, dictada en causa rol No 5741-2005; Corte de Apelaciones de TalCa, sentencia de 28 de septiembre de 2005, dictada en causa rol No 432-2005; Corte de Apelaciones de RancaGUA, sentencia de 1 de octubre de 2004, dictada en causa rol No 112-2004.

4 Así, Matus Acuña / Van Weezel de la Cruz (2002) 369. En contra, admite la aplicación del artículo 68 bis CP después de una compensación racional, Garrido Montr, Mario (2005). Derecho Penal, tomo I, Parte General, 2a ed., Santiago: Editorial Jurídica de Chile, p. 334, aunque sin ofrecer mayores argumentos.

5 Entre otros, Cury Urzúa, Enrique (2009). Derecho Penal. Parte General, 9a ed., Santiago: Ediciones Universidad Católica de Chile, p. 769; Bullemore, Vivian / Mackinnon, John (2007). Curso de Derecho Penal, tomo I, Parte General, 2a ed., Santiago: LexisNexis, 2007, pp. 177 ss.; Labatut Glena, Gustavo (2000). Derecho Penal, tomo I, 9a ed. actualizada por Julio Zenteno Vargas, Santiago: Editorial Jurídica de Chile, p. 277; Del Villar Brito, Waldo (1985). Manual de Derecho Penal. Parte General, Valparaíso: Edeval, p. 315; RudNiCK VizCarRa, Carolina (2007). La compensación racional de circunstancias modificatorias en la determinación judicial de la pena, Santiago: LexisNexis, p. 39; NÁquira Riveros, Jaime et al. (2008). "Principios y penas en el Derecho penal chileno", en Revista Electrónica de Ciencia Penal y Criminología, No 10, p. 49. Disponible en http://criminet.ugr.es/recpc/10/ recpc10-r2.pdf [fecha última visita: 26 de enero de 2011]. Por su parte, ETcheberRY, Al- 
A nuestro juicio, sin embargo, un planteamiento que aplique el señalado artículo cuando después de una compensación entre atenuantes y agravantes subsiste una atenuante muy calificada, no infringe la legalidad formal. En efecto, la literalidad de la disposición solo permite sostener que ella prevé la consecuencia jurídico-penal de la presencia de una sola atenuante -muy calificada-, pero no prejuzga acerca de si esa atenuante debe ser la única circunstancia modificatoria que acompaña al hecho desde el inicio del proceso de determinación de la pena aplicable, o si ella es la única subsistente tras la compensación racional entre agravantes y atenuantes que, en general, permiten los artículos 65 a 68 CP.

Por otro lado, para poder sostener que el tenor literal del artículo 68 bis CP impide su aplicación después de una compensación racional entre circunstancias modificatorias de orden inverso, el legislador tendría que decirlo explícitamente, incluyendo la expresión "sin que concurra ninguna agravante" u otra similar, pero no lo hace, forma de redacción que, en cambio, sí utiliza en los cuatro artículos inmediatamente anteriores al que nos concierne. En consecuencia, la literalidad de la disposición no solo tolera su aplicación a los casos en que después de una compensación racional entre atenuantes y agravantes, subsiste una atenuante que se estima muy calificada ${ }^{6}$, sino que incluso la sugiere.

\section{2) EL ARGUMENTO HISTÓRICO}

Suele invocarse también una consideración histórica en apoyo de la tesis que criticamos. El artículo 68 bis CP fue incorporado por la Ley No 17.772, de 27 de septiembre de 1972, la que modificó, entre otros, el art. 65 CP. Esta última disposición, aplicable cuando la ley señala al delito una sola pena indivisible, facultaba al tribunal para rebajar la pena en un grado cuando hubiera dos o más circunstancias atenuantes o una muy calificada y ninguna agravante. La mencionada ley eliminó la referencia a una atenuante muy calificada y creó el artículo 68 bis. El argumento que se acostumbra esgrimir es el siguiente: que de este modo la ley habría querido regular los efectos de una atenuante muy calificada con carácter

fredo (1998). Derecho Penal. Parte General, tomo II, $3^{\text {a }}$ ed., Santiago: Editorial Jurídica de Chile, reimpresión 1999, p. 183, reproduce el texto del artículo 68 bis $\mathrm{CP}$, pero agrega que se aplica cuando concurre una atenuante muy calificada "y ninguna agravante" -algo que no se desprende del tenor de la disposición-, sin justificar la razón de lo que añade. En este mismo sentido, implícitamente, Politoff Lifschitz, Sergio / Matus Acuña, Jean Pierre / Ramírez Guzmán, María Cecilia (2004). Lecciones de Derecho Penal Chileno. Parte General, $2^{a}$ ed., Santiago: Editorial Jurídica de Chile, pp. 529-533.

6 En este sentido, véase la opinión de Garrido MuÑoz, Osvaldo, "Las penas y su aplicación en Chile". Disponible en http://www.monografias.com/trabajos81/penas-aplicacion-chile/ penas-aplicacion-chile.shtml, p. 59 [fecha última visita: 21 de enero de 2011]. 
general, para todos los marcos penales a los que aluden los artículos 65 a $68 \mathrm{CP}$ (una sola pena indivisible, dos penas indivisibles, un grado de una pena divisible o los demás casos posibles, respectivamente), y no solo para el seńalado en el artículo 65. De ello se desprendería que el requisito de que no concurriera ninguna agravante, que se exigía -y se sigue exigiendo- para el efecto que se preveía en el artículo $65 \mathrm{CP}$-que actualmente consiste en una rebaja de pena en uno o dos grados-, hoy sería exigible para el efecto previsto en el artículo 68 bis.

Según nuestra opinión, el recurso al elemento histórico de interpretación no conduce necesariamente a la tesis que enjuiciamos. Es cierto que fue una misma ley la que modificó el artículo 65 e incorporó el artículo 68 bis, pero de eso no se deduce que haya sido intención del legislador (la interpretación histórica de la ley consiste, precisamente, en desentrañar cuál ha sido dicha intención) impedir la aplicación del nuevo artículo 68 bis para los casos en que subsista una atenuante muy calificada después de una compensación racional entre atenuantes y agravantes. Una revisión exhaustiva de la tramitación parlamentaria de la Ley No 17.772 no permite sostenerlo. En efecto, ni en el mensaje presidencial con que se inició dicha tramitación, ni en la discusión habida en las sesiones de sala y de comisión, se expresó y tampoco se insinuó algo así. No hay, entonces, antecedentes históricos concretos sobre la base de los cuales realizar una afirmación semejante. Lo único que es posible concluir -algo obvio, pero importante de destacar, por las razones que se darán más adelante- es que se quiso que la posibilidad de rebajar la pena en un grado por la concurrencia de una atenuante muy calificada, no dependiera del marco penal aplicable al delito de que se trate, sino que fuera común a todo el sistema de determinación de los efectos de las circunstancias modificatorias en el proceso de individualización de la pena.

Por otro lado, la utilización del método de interpretación histórica sugiere justamente lo contrario a lo que postula la tesis que criticamos. En efecto, es evidente y de ello quedó constancia durante la tramitación parlamentaria de la mencionada ley, que lo que ella buscaba era beneficiar a los imputados ${ }^{7}$. Se pretendía mejorar considerablemente la situación de los condenados para los efectos del proceso de determinación de la pena que en definitiva se les impusiera ${ }^{8}$. Pues bien, la interpretación del

Como lo dijo, entre otros, el diputado Santibáñez en la sesión de la Cámara del día 11 de abril de 1972. Diario de sesiones de la Cámara de Diputados, sesión 7a , martes 11 de abril de 1972, p. 355. Así también se lo expresó en el mensaje presidencial que dio inicio a la tramitación parlamentaria de la mencionada ley.

8 El interés en beneficiar a los imputados resultaba palmario no solo en este aspecto de la ley, sino también en otros, como por ejemplo, en la modificación que introdujo en el artículo $18 \mathrm{CP}$, para permitir la aplicación retroactiva de la ley penal más benigna incluso cuando esta es posterior a la sentencia condenatoria firme, y en el cambio que hizo en el primer inciso del artículo $450 \mathrm{CP}$, para reducir el grupo de delitos cuya comisión se castiga con la pena de la consumación desde que se encuentran en grado de tentativa. 
artículo 68 bis que impide su aplicación para los casos en que subsista una atenuante muy calificada después de una compensación racional entre circunstancias modificatorias de distinto orden, no parece compatible con la benignidad explícitamente buscada por el creador de la ley, ya que se aplicaría en muy pocos casos. En muchas ocasiones sucede que en la realización de un hecho delictivo se presentan diversas circunstancias modificatorias, tanto atenuantes como agravantes, casos en los cuales el mencionado artículo no recibiría aplicación de acuerdo con la interpretación que rechazamos, la que reduce en demasía la benignidad perseguida por el legislador.

\section{3) EL ARGUMENTO SISTEMÁTICO}

Un sector de la doctrina afirma que una interpretación sistemática conduciría a sostener la tesis que criticamos. El argumento consiste en constatar que la rebaja de un grado que contempla el artículo 68 bis para la concurrencia de una atenuante muy calificada se cuenta desde el mismo punto de partida que las rebajas de uno, dos o tres grados que prevén los artículos 65 a 68 para la concurrencia de dos o más atenuantes (o sea, desde el mínimo legal), lo que permite concluir a quienes lo esgrimen que los efectos de tales reglas no se superponen?

Según nuestro modo de pensar, el hecho constatado -que las mencionadas rebajas de grado se cuentan desde el mismo punto de partida- es cierto. Y también lo es, por lo mismo, que las reglas que aluden a tales rebajas no se superponen. Pero ello en modo alguno significa que el artículo 68 bis no pueda aplicarse después de una compensación racional entre atenuantes y agravantes. Que las señaladas rebajas se cuenten desde el mismo punto de partida no tiene nada de raro, porque se trata de reglas cuyos supuestos de aplicación son diferentes en cuanto al número de atenuantes que se exige que concurran. Las reglas que permiten la rebaja de hasta tres grados exigen la concurrencia $-a b$ initio o después de una compensación racional entre circunstancias modificatorias de distinto signo- de dos o más atenuantes. En cambio, la que permite la rebaja de solo un grado exige la concurrencia de una única atenuante. Luego, efectivamente no son reglas que se superponen. Pero ello no prejuzga acerca de lo que nos interesa, porque aun cuando se sostenga que el artículo 68 bis puede aplicarse a una única atenuante subsistente tras la compensación racional entre atenuantes y agravantes, es claro que este caso no queda cubierto por las reglas que permiten rebajar la pena hasta en tres grados. En consecuencia, no puede verse en esta línea argumentativa nada a favor de la tesis que enjuiciamos.

9 Así, Matus Acuña / Van Weezel de la Cruz (2002) 369 y ss. 
Lo único que sí puede concluirse a partir de esta argumentación es que cuando ab initio o después de la compensación racional concurren o subsisten varias atenuantes, el artículo 68 bis no puede aplicarse, aun cuando una de ellas sea muy calificada ${ }^{10}$. Por ejemplo, si concurren en el hecho tres atenuantes, una de las cuales es muy calificada, no podría el tribunal rebajar la pena hasta en tres grados conforme a lo que disponen los artículos 65 a 68 para la concurrencia de dos o más atenuantes, y además bajarla en un grado más de acuerdo con el artículo 68 bis.

Por otra parte, nos parece que una interpretación sistemática permite, al igual que lo que sucede con la interpretación histórica, concluir precisamente lo contrario de la tesis que criticamos. En efecto, de la lectura de los artículos 65 a 68 se desprende que la concurrencia de una sola atenuante, sea que se trate de la única circunstancia modificatoria que acompaña al hecho, sea que se trate de la única subsistente tras la compensación racional entre atenuantes y agravantes, no permite rebajar el marco penal en grado alguno. Si se trata de una sola pena indivisible, no se produce ningún efecto (art. 65); si se trata de una pena compuesta de dos indivisibles, se la debe aplicar en su grado mínimo (art. 66); si se trata de un grado de una pena divisible, se la debe aplicar en su minimum (art. 67), y si se trata de una pena compuesta de una o dos penas indivisibles y uno o más grados de otra divisible, o diversos grados de una pena divisible, se excluye la aplicación de su grado máximo (art. 68). Pues bien, dado que los mencionados artículos no permiten rebajar la pena en grado cuando concurre una sola atenuante, y considerando la benignidad que inspiró al legislador de la Ley No 17.727, puede sostenerse que es voluntad actual de la ley permitir esa rebaja por la concurrencia de una sola atenuante -repetimos-, sea que se trate de la única que acompańa al hecho, sea que se trate de la única que subsiste tras la compensación racional. En otras palabras, el artículo 68 bis vino a solucionar un problema práctico derivado de la imposibilidad de una sola atenuante de rebajar la pena, agravado por la frecuente severidad de esta.

Esto permite explicar el porqué de los términos utilizados por el artículo 68 bis. La expresión con que comienza su texto ("Sin perjuicio de lo dispuesto en los cuatro artículos anteriores") significa que su contenido debe entenderse sin desmedro de toda la regulación contemplada en los artículos 65 a 68, dentro de la cual se encuentran las reglas sobre compensación racional entre atenuantes y agravantes y sobre aplicación a la eventual atenuante subsistente tras ella, del efecto previsto para la concurrencia de solo una atenuante, el que, como hemos visto, no alcanza la intensidad de una rebaja de pena en grado. Lo que el artículo 68 bis hace, entonces, es permitir la rebaja de grado si esa atenuante -única que

10 Matus Acuña / Van Weezel de la Cruz (2002) 371. 
acompaña al hecho o que subsiste tras la compensación racional- es muy calificada. En otras palabras, es como si el texto del artículo 68 bis se repitiera en cada uno de los artículos anteriores, inmediatamente después de regularse el efecto de la concurrencia de solo una atenuante: si no es calificada, se producirá dicho efecto; si lo es, se podrá rebajar la pena en un grado. Por ejemplo, cuando el intérprete constata que en el artículo 66 se dispone que si la pena es compuesta por dos indivisibles y "solo concurre alguna circunstancia atenuante" - sea ab initio, sea postcompensación racional-, debe aplicarse la pena en su grado mínimo, acto seguido debe recordar que si solamente concurre una atenuante muy calificada, se puede imponer la pena inferior en un grado al mínimo (art. 68 bis). De este modo, se confirma que carece de solidez el argumento literal de la tesis que criticamos, que atiende al hecho de que el artículo 68 bis exige que "solo concurra una atenuante muy calificada", ya que se trata exactamente de la misma terminología que emplea la ley en los artículos que le preceden.

En síntesis, para comprender adecuadamente el sistema de los efectos de las circunstancias modificatorias en la determinación del marco penal de un delito, debe entenderse que lo que prevé el artículo 68 bis está siempre presente en todas las reglas sobre concurrencia de solo una atenuante, contenidas en los artículos que le anteceden.

\section{4) LAS CONSECUENCIAS PRÁCTICAS}

Como corolario de todo lo dicho, puede afirmarse que cuando la ley señala una pena que es compuesta de dos indivisibles (art. 66), y concurre en el hecho solamente una atenuante, sea que se trate de la única circunstancia modificatoria que lo acompaña, sea que se trate de la única que subsiste tras la compensación racional entre atenuantes y agravantes, debe distinguirse según si esa atenuante es o no muy calificada: si lo es, corresponde imponer la pena inferior en un grado al mínimo de la señalada al delito; si no lo es, debe aplicarse la pena en su grado mínimo.

Cuando la pena señalada al delito es un grado de una divisible (art. 67), y hay en el hecho solo una atenuante, sea que esta concurra desde el inicio del proceso de determinación de la pena a imponer, sea que subsista tras la compensación racional entre circunstancias modificatorias de orden inverso, también debe distinguirse si es o no muy calificada: si lo es, se debe rebajar la pena en un grado; si no lo es, se debe aplicar la mitad inferior del grado de que consta la pena.

Si la pena se compone de uno o más grados de una divisible y una o dos indivisibles, o bien, de diversos grados de una divisible (art. 68), y concurre en el hecho solo una atenuante, bien se trate de la única circunstancia modificatoria que lo acompaña, bien se trate de la única que resta 
tras la compensación racional entre atenuantes y agravantes, nuevamente se debe distinguir según si es o no muy calificada: si lo es, debe imponerse la pena inferior en un grado al mínimo de la señalada al delito; si no lo es, quedará excluida la aplicación del grado máximo.

En cambio, cuando la ley señala al delito una sola pena indivisible (art. 65), los efectos de la concurrencia de una sola atenuante se encuentran mucho más limitados, primero, porque se circunscriben al caso en que ella sea la única circunstancia modificatoria que desde el comienzo del proceso de determinación de la pena aplicable acompañe al hecho, y segundo, porque solo se verifican si ella es muy calificada. Efectivamente, por un lado, no cabe aplicar tales efectos cuando esa atenuante subsista tras una eventual compensación racional, por la sencilla razón de que la ley no permite efectuar aquí tal compensación ${ }^{11}$. A diferencia de lo que sucede en los artículos 66 a 68, que sí contemplan la posibilidad de compensar atenuantes y agravantes, el artículo 65 no lo hace, por lo que en este supuesto, el único caso en que la concurrencia de una sola atenuante puede producir efectos en la configuración del marco penal, tiene lugar cuando ella es la única circunstancia modificatoria que acompaña al hecho. Y por otro, tampoco cabe distinguir aquí entre una sola atenuante muy calificada y otra que no lo es, ya que el artículo 65 no atribuye efecto alguno a la concurrencia de una sola atenuante. Entonces, solo resulta aplicable el artículo 68 bis, cuyo efecto -rebaja de la pena en un gradoexige la presencia de una sola atenuante muy calificada. Por lo tanto, es este el único caso (delito al que la ley señala una sola pena indivisible) en que la aplicación del artículo objeto de nuestro estudio exige que la atenuante muy calificada sea la única circunstancia modificatoria que acompañe al hecho desde el inicio del proceso de determinación de la pena a imponer.

\section{CONCLUSIONES}

Para finalizar este trabajo, hemos decidido dejar expuestas a modo de conclusiones, las principales afirmaciones efectuadas a lo largo del mismo.

1) El tenor literal del artículo 68 bis no solo no impide su aplicación cuando después de una compensación racional entre circunstancias modificatorias de distinto orden subsiste una atenuante muy califica$\mathrm{da}$, sino que incluso la sugiere.

11 Esto no puede ser considerado una laguna, como lo demuestra el hecho de que a pesar de que en 1972 la disposición fue modificada por la mencionada Ley No 17.727, no se decidió introducir aquí la posibilidad de compensar atenuantes y agravantes. CuRY URzúa (2009) 767. 
2) No existen antecedentes históricos concretos que permitan afirmar que haya sido intención del legislador impedir la aplicación del artículo 68 bis a los casos en que subsista una atenuante muy calificada después de una compensación racional entre atenuantes y agravantes. El método de interpretación histórica de la ley sugiere precisamente lo contrario.

3) Cuando ab initio o después de la compensación racional entre atenuantes y agravantes concurren o subsisten varias atenuantes, el artículo 68 bis no puede aplicarse, aun cuando una de ellas sea muy calificada.

4) Una interpretación sistemática de la ley permite concluir que el artículo 68 bis puede aplicarse no solo cuando hay una atenuante muy calificada como única circunstancia modificatoria que acompaña al hecho, sino también cuando es la única circunstancia que subsiste tras la compensación racional entre atenuantes y agravantes. Una adecuada comprensión del sistema de los efectos de las circunstancias modificatorias en la determinación del marco penal de un delito, exige entender que lo que dicho artículo prevé está presente en todas las reglas sobre concurrencia de solo una atenuante, contenidas en los artículos que le preceden.

5) Cuando la pena que señala la ley al delito es compuesta de dos indivisibles (art. 66), o es un grado de una divisible (art. 67), o se compone de uno o más grados de una divisible y una o dos indivisibles, o bien, de diversos grados de una divisible (art. 68), y concurre en el hecho solamente una atenuante, sea que se trate de la única circunstancia modificatoria que lo acompańa, sea que se trate de la única que subsiste tras la compensación racional entre atenuantes y agravantes, debe distinguirse según si esa atenuante es o no muy calificada: si lo es, corresponde imponer la pena inferior en un grado al mínimo de la señalada al delito (art. 68 bis); si no lo es, debe aplicarse la pena en su grado mínimo, o la mitad inferior del grado de que se compone la pena, o excluirse la aplicación del grado máximo, respectivamente.

6) En cambio, cuando la ley señala al delito una sola pena indivisible (art. 65), no procede distinguir entre una sola atenuante muy calificada y una que no lo sea, para la posible alteración del marco penal. Este únicamente puede ser modificado si hay una sola atenuante muy calificada, y siempre que sea la única circunstancia modificatoria que acompañe al hecho desde el inicio del proceso de determinación de la pena a imponer. 


\section{BIBLIOGRAFÍA}

- Bullemore, Vivian / Mackinnon, John (2007). Curso de Derecho Penal, tomo I, Parte General, 2a ed., Santiago: LexisNexis, 2007.

- Choclán Montalvo, José Antonio (1997). Individualización judicial de la pena. Función de la culpabilidad y la prevención en la determinación de la sanción penal, Madrid: Colex.

- Cury Urzúa, Enrique (2009). Derecho Penal. Parte General, 9a ed., Santiago: Ediciones Universidad Católica de Chile.

- Del Villar Brito, Waldo (1985). Manual de Derecho Penal. Parte General, Valparaíso: Edeval.

- Demetrio Crespo, Eduardo (1999). Prevención general e individualización judicial de la pena, Salamanca: Ediciones Universidad de Salamanca.

- Etcheberry, Alfredo (1999). Derecho Penal. Parte General, tomo II, $3^{a}$ ed., Santiago: Editorial Jurídica de Chile, reimpresión 1999.

- Garrido Montt, Mario 82005). Derecho Penal, tomo I, Parte General, 2a ed., Santiago: Editorial Jurídica de Chile.

- Garrido Muñoz, Osvaldo. "Las penas y su aplicación en Chile". Disponible en el sitio web http://www.monografias.com/trabajos81/ penas-aplicacion-chile/penas-aplicacion-chile.shtml [fecha última visita: 21 de enero de 2011].

- Labatut Glena, Gustavo (2000). Derecho Penal, tomo I, 9a ed. actualizada por Julio Zenteno Vargas, Santiago: Editorial Jurídica de Chile.

- Mañalich Raffo, Juan Pablo (2010). “'Discrecionalidad judicial en la determinación de la pena en caso de concurrencia de circunstancias atenuantes de la responsabilidad penal?", en Informes en Derecho, No 7, octubre, doctrina Procesal Penal 2009, Centro de Documentación de la Defensoría Penal Pública.

- Matus Acuña, Jean Pierre / Van Weezel de la Cruz, Alex (2002). "Comentario a los artículos 50 a 73", en Politoff Lifschitz, Sergio / Ortiz Quiroga, Luis (dirs.), Matus Acuña, Jean Pierre (coord.): Texto y comentario del Código Penal chileno, tomo I, Libro Primero - Parte General, Santiago: Editorial Jurídica de Chile.

- Mir Puig, Santiago (2004). Derecho Penal. Parte General, 7a ed., Montevideo - Buenos Aires: B de F.

- Náquira Riveros, Jaime et al. (2008). "Principios y penas en el Derecho penal chileno", en Revista Electrónica de Ciencia Penal y Criminologia, No 10. Disponible en http://criminet.ugr.es/recpc/10/ recpc10-r2.pdf [fecha última visita: 26 de enero de 2011].

- Politoff Lifschitz, Sergio / Matus Acuña, Jean Pierre / Ramírez Guzmán, María Cecilia (2004). Lecciones de Derecho Penal Chileno. Parte General, 2a ed., Santiago: Editorial Jurídica de Chile. 
- Rudnick Vizcarra, Carolina (2007). La compensación racional de circunstancias modificatorias en la determinación judicial de la pena, Santiago: LexisNexis.

- Van Weezel de la Cruz, Alex (1997). "Compensación racional de atenuantes y agravantes en la medición judicial de la pena”, en Revista Chilena de Derecho, volumen 24, No 3. 